(1) Kian Soheil

\title{
The Consumptive Significance of Images and Interface Values in Cyberpunk Cities
}

\section{ABSTRACT}

Cyberpunk is one of the latest genres in the development of science fiction. The genre emerged during the $80 \mathrm{~s}$ and $90 \mathrm{~s}$, and in it the characters are confronted by an abundance of images and interface values. As a result, these images and values have become key identifying motifs of this genre. Referring to the theoretical conceptualizations of Adam Roberts about novum, and Lieven De Cauter on capsules and capsulization, the present study argues that the reason for the abundance of images and interface values is due to their facilitation of the consumption of novelties in cyberpunk cities. Within a scientific and rational discourse, images and interface values combine familiar and unfamiliar concepts and package them both as convenient commodities to be consumed by the characters of cyberpunk fiction. One of the key outcomes of such a combination, the study argues, is that the characters of cyberpunk fiction rely on the consumption of images and interface values as a convenient means to handle the overwhelming presence of technological and cybernetic advancements in the represented cities. This outcome turns the need to see and consume the cyberpunk world through images and interface values into an ideological necessity—or what can also be called a defense mechanism-for the characters against the technological shock of cybernetic advancements; a necessity whose qualities will be discussed in the study, as well.

Keywords: cyberpunk, the City, image, interface, novum, capsule. 


\section{INTRODUCTION}

The present study investigates the significance of the abundance of images and interface values as key image representations in cyberpunk cities. It will be argued that the plethora of images and interface values in cyberpunk cities is due to the convenience with which they provide the characters the opportunity to consume various commodities. The study believes that images and interface values of cyberpunk cities always fuse familiar and unfamiliar concept novelties, and the resulting items are presented to the characters in a safe and convenient manner. Furthermore, in such fusions, the characters are always reassured that the novelties presented to them through images and interface values are within scientific and rationalistic discourses. The presence of familiar concepts alongside unfamiliar novelties that reside within the rationalistic and logical discourses of science make the characters embrace the images and interface values of cyberpunk cities, resulting in a substantial increase in their production. Such features of images and interface values also make the characters deal with the overwhelming presence of technological, cybernetic advancements and their representations through taking shelter in other images and interface values. Identifying each other through technologically mediated images and profiles, spending leisure time in standardized and radically dwindled public spaces, and relying on images and interface values as the convenient and stereotypical means for knowledge acquisition are some of the usages of cybernetic capsules in cyberpunk cities.

This study uses theoretical conceptualizations of novum (plural form: nova) and capsules by Adam Roberts and Levian De Cauter, the two famous critics in science fiction and cyber cultural studies, to discuss the significance of images and interface values in cyberpunk fiction. In our analysis it will become apparent that the facilitation of consumption is the key reason why images and interface values become abundant in the cyberpunk city. ${ }^{1}$ In the first section, the role of the fusion of the familiar and the unfamiliar in facilitating convenient consumption in cyberpunk cities will be identified. To support Roberts's ideas as the theoretical scaffold of the study, pertinent references to Sherryl Vint's "Cyberpunk and Commodification" and other anthologized critics in Beyond Cyberpunk will be made. In Vint's article, it is mentioned that any unfamiliar and unknown concept (either artistic or technological) needs to be blended in —even uneasily_-with familiar and easily consumable concepts in cyberpunk fiction so that both the crude commodities and much more subtle and recondite concepts can be presented

1 The study uses "the cyberpunk city" and "cyberpunk cities" to refer to the represented cities and urban spaces in cyberpunk fiction. 
in tandem with each other. Using Gibson's comments on the genre, she argues that "authentic art survives in the era of the culture industry in ways other than separating itself from the material world" (111). This insistence on the impossibility of the separation of nuanced/artistic and materialistic concepts from each other makes Roberts's idea of nova dialectic. The study prefers the dialectic nature of his idea since it does not naively see an idealistic possibility of dissidence in the genre and its novelties, and, as Vint believes, does not commit itself to a "recidivist" understanding in which the critic and the artist try heroically to "control art, to slice away the bad [in this case the consumable and material aspects of art] and leave only the good. [in this case the unfamiliar and recondite technological and artistic concepts]" (101). Such a perspective is also in line with Fredric Jameson's understanding of the genre as a late capitalist one which "grasps the spirit and the impulse of the imagination of the multinationals in postmodernism, which in new writing like cyberpunk determines an excess of representational consumption" (321). In Jameson's view, cyberpunk is simultaneously capitalist and postmodernist since the coupling of these two ideological and discursive tendencies helps "the migration of concepts towards representations, where the thrill of multinational business has an outweighing attraction" for the denizens of a consumptive world such as the cyberpunk world (321). Considering these theoretical standpoints, the study sees the coupling of the materialistically familiar and unfamiliar elements in nova as the ideal capitalist strategy with which the wildest novelties in this postmodernist and capitalist world are propagated and consumed.

In the second section, the role of images in curbing the shock of the overwhelming presence of images and interface values of cybernetic advancements in cyberpunk cities will be examined. In this section, the consequences of turning consumption into an ideological defense mechanism against the technological shock will be enumerated in four points, as well. To put its claims within a theoretical framework, Lieven De Cauter's concept of capsularization will be employed. He argues that the higher number of technological advancements will result in more intense utilizations of some of these advancements as protective capsules against the overwhelming presence of technological novelties most of whose nature is visual. He says, "the more physical and informational speed increases, the more man will need capsules" (95). ${ }^{2}$

2 It needs to be acknowledged that if a scholar decides to extend De Cauter's conceptualization of capsules into the study of the spatial aspects of cyberpunk cities, he/she may benefit from employing De Cauter's idea alongside the concept of the Metabolist architecture (which is a capsularized architectural scheme). For more details on the Metabolist architecture, refer to Regean Legault's Anxious Modernisms and William Gardner's upcoming The Metabolist Imagination. 
The novels used to support the argument of the study are selected works by William Gibson (Virtual Light, 1993; Idoru, 1996; All Tomorrow's Parties, 1999) and Bruce Sterling (Schismatrtix Plus, 1985; Island in the Net, 1988), two of the early and seminal cyberpunk writers, alongside Richard Morgan's Altered Carbon (2002). The reason for including these texts relates to the density of the cyberpunk genre and the fact that a study must consider the works of both the early and late cyberpunk writers in order to support its academic claims.

\section{IMAGES: THE CONVENIENT CONSUMPTIVE MEANS OF CYBERPUNK CITIES}

We argue that the key reasons for the presence of images and interface values in cyberpunk cities is the convenience they provide for the characters' consumption of various types of new commodities. In order to investigate the facets of such a consumptive convenience, the study utilizes Adam Roberts's conceptualization on novum (plural form: nova). ${ }^{3}$ Referencing Darko Suvin's terminology, Adam Roberts believes that the "point of difference, the thing or things that differentiate the world portrayed in science fiction from the world we recognize around us, is the crucial separator between science fiction and other forms of imaginative or fantastic literature" (6). Like Suvin, Roberts calls these points of difference "novum" (plural form: nova). Spaceships, interplanetary or interstellar travel, aliens and the encounter with aliens, mechanical robots, genetic engineering, biological robots ("androids"), computers, advanced technology, virtual reality, and images and interface values which represent these novelties are some of the instances of nova in science fiction. These nova defamiliarize the science fictional world from the mundane world for the characters. In Roberts's opinion, a novum has mundane and nonsupernatural justification. The characters of a science fictional world should not seek refuge in unknown metaphysics in order to acknowledge a science fictional novum in the fiction. However, the justification and explanation around a novum should not be purely scientific and should be on the basis of a "discourse of science" (Roberts 9). According to Roberts, the science fictional devices and novelties of a particular short

\footnotetext{
3 It needs to be acknowledged that in "Towards a Poetics of Cyberpunk," while discussing cyberpunk fiction, Brain McHale did present the idea of an uneasy coexistence of rational and familiar extrapolation and unfamiliar and fantastic speculation in the genre. The present study prefers Roberts's conceptualization of nova since the idea can more efficiently discuss the consumptive significance of each and every novelty in the science fictional world of the genre.
} 
story or a novel should not divulge the details of their rational or scientific functionality and should, at their surface levels, espouse rationality and scientism. The nova should never be so complicated as to hamper characters' understanding of their functionality and at the same time, are not turned into bland representations of our mundane world. In this sense, they situate themselves between "cognition and estrangement; they are both relevant and challenging to the ordinary world" (Roberts 16). This inbetweenness makes science fictional nova commodifiable and conveniently consumable for the characters of science fiction.

According to Roberts, then, there are two conditions that constitute a novum: being familiar and worldly and at the same time being unfamiliar and discontinuous with the ordinary surroundings of the world and having only a façade of scientism and rationalism. The two features of a novum are represented in the usage of stack and sleeves in Altered Carbon. By ingraining people's memories in devices called stacks, the novel shows that these stacks can be implanted in various sleeves (preconstructed bodies) as the stacks' interface values. The characters are not aware of the details of how these stacks function and if, on occasion, there is some technical talk, it is devised to give the coloring of scientism and rationality to the novel. Metaphorically speaking, the stacks are regarded as interface devices and means for accessing and actualizing all the behavioral and mental aspects of a human being in the novel that can be easily transferred to different bodies. The stacks are interface values for the chaotic and incomprehensible intricacies of a human being. Such values make the act of identification of spiritual and identity qualities convenient for the characters. The sleeves that can house the stacks are simultaneously different and similar to each other, since they are realized around a mental selection, gathered in the stack. The stack is just a selection and cannot give originality to all the sleeves. It is neither a reference point nor a deep structure; it is the raw, chaotic and randomized programming language around which a plethora of sleeves are constructed for people's consumption. The stack only parodies the differences between these sleeves, since all of them, although seeming different from each other, cannot escape the range of possibilities the stack has provided for them. Such parodistic reading of superficial differences between the stacks-as one of the nova of the novel一attests to their capitalist nature. This nature presents superficially devised differences and instances of unfamiliarity within the consumptive fabric-which is the only recognizable deep structure of the novumof the stacks. In this sense, the characters of the novel do not expect the emergence of anything dissident or revolutionary from the strange novelties of the nova such as the stacks since their perspective is not, as 
Vint believes, "recidivist"; the belief that insists on futilely "slicing away and controlling" something genuinely different and oppositional from the capitalist fabric of the cyberpunk world (101). In a discussion about the stacks, the protagonist of the novel, Tak, comments on the relation between sleeves and stacks as follows:

Most virtual systems recreate you from self images held in the memory, with a common-sense sub-routine to prevent your delusions from impinging too much. I generally come out a little taller and thinner in the face that I usually am. In this case, the system seemed to have scrambled a myriad of different perceptions from a long list of sleeves. I'd seen it done before, as a technique, but most of us grow rapidly attached to whatever sleeve we are living in, and that form blanks out previous incarnations. (Morgan 195)

Sleeves and even stacks are temporary "incarnations" that are easily replaceable and at the same time are based on "a long list of [previously used] sleeves." Such a characteristic of replaceability means that the novelty of a more technologically advanced sleeve should be established upon previous versions so that it can tempt users to use them. Sleeves exercise "discontinuity" (Roberts 210) in their relations to previous versions and at the same time, they have some "continuity" with them (210), and as a result users "grow rapidly attached to whatever [previous] sleeve [they] are living in" (Morgan 195). Even the brief preliminary explanation of how sleeve-making functions is devised to give the characters the vindication that the nova of the novel are "drained of transcendental or metaphysical aura and [need to be relocated] in the material world" (Roberts 170). The author does not intend to explain away the detailed workings of either stacks or sleeve-making, but rather intends to locate them between the familiar and unfamiliar worlds of the characters. As Jameson believes in the capitalist setting of the cyberpunk world, "what is at stake is knowhow and knowledge of the system itself, [and] and the knowledge is not particularly scientific, and merely involves initiation into the way the system functions" (352). In this novel, stacks as one of its science fictional nova carries such a representational connotation of scientism. In order to consume and trust the new technologies, offered by the new-sleeving facilities, the characters need to be assured within a pseudo-scientific discourse (also known as scientism) that despite the attractive improvements of the new technologies, there is still continuity between the new and old technologies, and yet they are charmingly different from the previous technologies.

The quality of the uneasy fusion of familiar and unfamiliar can also be seen in Island in the Net, in which the characters are faced with a strange image from their historical past. In this novel, the narrator discusses the 
origins of the city name "Singapore" and how it denotes no originality and is realized through manipulation of mythological fragments. As he writes:

\begin{abstract}
Singha Pura meant "Lion City." But there had never been lions on Singapore island. The name had to make some kind. So local legend said the "lion" had been a sea monster. On the opposite side of Singapore's National Stadium, a human sea lifted their flash cards and showed Laura their monster. The Singapore "merlion," in a bright mosaic of cardboard squares. The merlion had a fish's long, scaled body and the lion head of the old British Empire. They had a statue of it in Merlion Park at the mouth of the Singapore River. The thing was thirty feet high, a genuinely monstrous hybrid. East and West like cats and fishes-never the twain shall meet. Until some bright soul had simply chopped the fish's head off and stuck the lion's on: And there you had it: Singapore. (Sterling, Island 122-23)
\end{abstract}

Even their mythological manipulation cannot be referred to a holistic and unique image and is a strange "monstrous hybrid" (122). This passage shows that the characters in the novel acquire some comprehension from the foundational myth of a city such as Singapore through the grotesque fusion of familiar mythological concepts and the unfamiliar nature of their manipulation. This image demonstrates that even the native citizens of a city cannot pinpoint a historical or cultural anchorage in the development of their city spaces and prefer to rely on an image. Singapore becomes a novum that, despite having some unknown aspects, becomes acceptable since it is put in a seemingly rational discourse with some tangential overtones of foundation myths and historical backgrounds of some wellknown cities in mankind's history.

In another example from Schismatrix Plus, one can observe how reference to ancient cultures can express a crude and inaccurate relativism that appoints tradition and culture only as the substance for the uneasy blend of familiar and unfamiliar. The conflict of this fusion can be seen in the conversation of Lindsay and Ryumin, two leading characters, regarding an adaptation of the story of Helen:

"I have the feeling I've heard this story before," he said. He flipped through the printout's pages. The margins were thick with cartoon stick figures scribbled there for the illiterate. "Let me see if I have it right. A group of pirates in the Trojan asteroids have kidnapped a Shaper woman. She's some kind of weapons specialist, am I right?" . . "The Shapers are terrified by what the pirates might do with her expertise. So they form an alliance and put the pirates under siege. Finally they trick their way in and burn the place out." Lindsay looked up. "Did it really happen, or didn't it?" "It's an old story," Ryumin said. "Something like that actually happened once; 
I feel sure of it. But I filed off the serial numbers and made it my own." (Sterling, Schismatrix 42)

The only reason that Ryumin wants to direct this script is to make money through the audience, who are pirates. They will recognize some of the maritime jargon in the play and enjoy consuming a cultural artifact of the ancient time in fragmented and commodified collection. Like the example from Island in the Net about Singapore, in Schismatrix Plusit it is observed that even the patriotic sense one gets out of a play or the mythological and historical background of a city is the result of imagistic and interface values. These values only facilitate convenient knowledge acquisition and acceptance for the characters, since they can easily accept and consume the strangeness of these values as well-packaged products that have some common denominators with their pre-defined knowledge. Using Jameson's reasoning about late capitalism, one can see that only "an excess of representational consumption" is the impetus behind such unusual appropriation of mythic concepts in the name of a city and in the storyline of a dramatic adaptation (321). Through such an excess late capitalism can conveniently blend any unfamiliar peculiarity (e.g., cultural or scientific) with familiar representations whose nature is imagistic. In the example from Island in the Net, it can be argued that the wrongful recontextualization of a mythological tale facilitates knowledge acquisition for a bunch of pirates, since Ryumin, the author of the play, does not intend to create a culturally diversified dialogue between a foreign culture and the native culture of pirates. Without engaging with the culture, he only wants to present his community with an instance of cybernetic/science fictional novelty, a novum, with which both their familiar and unfamiliar horizons of knowledge and expectations can be conveniently conflated.

The uneasy conflation of familiar and unfamiliar can also be seen in Virtual Light. In order to introduce the sprawling setting of the city, the novel utilizes the familiar framework of a bridge and yokes upon it the idea of sedimentation which is a foreign, heterogeneous and incompatible superimposition upon a bridge whose conventional function is to facilitate movement, flow and transit. ${ }^{4}$ Although later in the novel, the narrator tends to see in the bridge an instance of Thomasson ${ }^{5}$ - and justifies this

4 By conventional function, the article refers to the discourse of bridge as a means of transportation which was established after the Industrial Revolution (Tatsumi 117).

5 Thomasson or Hyperart Thomasson is a type of conceptual art named by the Japanese artist Akasegawa Genpei in the 1980s. It refers to a useless relic or structure that has been preserved as part of a building or the built environment, which has become a piece of art in itself. Identification of the artistic nature of the relic is determined by ordinary passersby rather than professional artists. 
superimposition artistically-he does emphasize the commercial reason ("dreams of commerce") for such an uneasy coupling of disparate elements on the bridge in his first description of it:

Its steel bones, its stranded tendons, were lost within an accretion of dreams: tattoo parlors, gaming arcades, dimly lit stalls stacked with decaying magazines, sellers of fireworks, of cut bait, betting shops, sushi bars, unlicensed pawnbrokers, herbalists, barbers, bars. Dreams of commerce, their locations generally corresponding with the decks that had once carried vehicular traffic; while above them, rising to the very peaks of the cable towers, lifted the intricately suspended barrio, with its unnumbered population and its zones of more private fantasy. (Gibson, Virtual 48)

The accumulation of all such places of business with the excuse of creating a Thomasson curio in the middle of a city is an instance of the most covert strategy of capitalism to propagate consumption under the ruse of either an agendaless artistic creation upon the bridge-which can be identified by ordinary people_or a place of decadent and dissident experience (zones of private fantasy). In this sense, giving every denizen of the cyberpunk world of the novel the capability to be a connoisseur of art is the price which capitalism is prepared to pay for propagating the utmost consumption of the bridge as a novum. What matters is that this novum showcases its peculiarity within the familiar but appropriated setting of the bridge, and gains profit for the city. As Takayuki Tatsumi believes, "Gibson's Bay Bridge becomes well known all over the [fictional] world of the novel and attracts many international sightseers eager to see its junk-artistic atmosphere" (113). Even if there are some elements of genuine art, as Tatsumi emphasizes, they need to be represented through a commercially driven tourist attraction. Acquiring such capitalist, nonromantic and dialectic understanding of the wildest artistic innovation brings us close to the non-recidivist understanding which Vint promotes about the genre and its capitalist nature. This non-recidivist understanding shows the capacity of capitalism to abide by a "self-recycling logic" that "jeopardizes the distinctions between technopolis and junkyard, city and bridge, the homeless and the Thomassonians," and familiar and unfamiliar elements in the cyberpunk world, especially its cybernetic nova such as the bridge figure (Tatsumi 120).

The convenience of consumption of cyberpunk images and interface values is due to being science-fictional nova. These nova have an oscillating fluidity between familiar elements, on the one hand, and unfamiliar elements on the other. Such an oscillation allows them to function within a scientific discourse, and at the same time gives them a certain allure. 
The characters need to feel certain of the convenience and safety of the represented technology (what we called novum) while being enticed with its attractive novelty. Under such circumstances, they know that the most unpredictable and implausible image or interface value in the cyberpunk world will eventually be embraced and consumed since it will be suitably explained through recognizable, familiar and plausible criteria.

\section{IMAGES: THE CONVENIENT MEANS AGAINST THE SHOCK OF CYBERNETIC ADVANCEMENTS}

Apart from the consumptive convenience of images and interface values as the key constituents of cyberpunk nova, the convenience of these nova is due to their ability to contain the overwhelming assailment of all the technological and cybernetic advancements of cyberpunk cities and their interface-based, imagistic representations. It is as if cyberpunk interface values and images (i.e. nova) "capsulize" people against the initial shocking attack of all the images and interface values. According to Lieven De Cauter, with the increase in the demand for new technologies and their pertinent tools and devices both in the real and fictional worlds, mankind sees the necessity to "protect" itself against being overwhelmed by technological novelties and their imagistic impact (De Cauter 94). In order to acquire an understanding of all the technological advancements, mankind should enter the infinite world of technological novelties through devices and tools that De Cauter calls "capsules." Capsules are mankind's attempt, both in the real and fictional worlds, to tackle "shock." Referencing critics such as McLuhan and Freud, De Cauter argues:

That modern man is under constant attack of an overload of stimuli (shocks), which induce a sort of defense mechanism. Therefore the more physical and informational speed increases, the more man will need capsules. ... The convinced city dwellers have to fight the mechanism of the suburbanization of daily life: cars, telephones (mobile or fixed), televisions and computers (with Internet connection) are the basic tools (and causes) of this process. (De Cauter 95-96)

In his view capsules are the sign that mankind is attacked more and more by external forces of technological advancements and capsules are mankind's last means of defense. Mankind is put in a position in which seeking help from imagistic capsules and nova become the only means of their survival and knowledge acquisition. As De Cauter believes, "when fear and the mechanism of defensible space takes over then we might see that this becomes another sort of iron law: Fear leads to capsularization 
and capsularizalion enhances fear" which can only be assuaged through utilization of further capsules (96). Therefore, cyberpunk characters are made to think that capitalist features of the conveniences of technology are less significant than the protection they provide against the very technologies that have necessitated the usage of such capsules and nova. As De Cauter points out, such a fear of not having a capsule through which one can handle the daunting force of technology, turns one's consumption into an ideology to which people will commit. People hate to be excluded from and remain dumbfounded by technology. Under such circumstances, all the blatant capitalist objectives behind the promotion of capsules will be covered up in the informational city and, consequently, in cyberpunk cities. Capsules present no utopian hope of dissidence to the denizens of the cyberpunk world. In this world, people become fully complicit in capitalist strategies. According to Tom Moylan, what they learn is to foster "a hope for [a set] of cultural practices that re-function the imposed technological harshness. What emerges is a way of using imposed systems that creates at least a certain play in that order, a space for maneuvers of unequal forces" (87). In the cyberpunk world, survival constitutes the heart of the "certain play" which people desperately seek, and they are aware that acknowledging the consumptive role of images and interface values in their lives is the first rule of even being included in the play.

In the cyberpunk world, the first consequence of the ideological need to consume through capsules is the fact that capsules become the only means of private and public discernment and knowledge acquisition. In Idoru, it is emphasized that people learn to be committed to the interface and imagistic values of celebrity culture. In order to identify criminals or locate their lost loved ones, they do not go to a sketch artist at the police station. They use the celebrity simulation technology. This technology presents the characters, who wanted to be alerted about the recognition of a wanted face (felon or family), with the nearest celebrity face they should identify. It is as if, in the midst of all the overwhelming images, advertisements and media propaganda in the novel, devising a capsule that can use familiar premises of science and cultural concepts, and the unexplainable, and recondite facial simulation technology becomes the only means for the characters' return to having a discerning identification. In the novel, the narrator talks about how the characters are encouraged towards reliance upon this technology:

Laney noticed something then that he knew from his encounters with celebs at Slitscan: that binary flicker in his mind between image and reality, between the mediated face and the face there in front of you. He'd noticed how it always seemed to speed up, that alternation, until 
the two somehow merged, the resulting composite becoming your new idea of the person. (Gibson, Idoru 128)

This "new idea," Laney believes, is more convenient since "it is rounded; it is complete; it is retrievable and it is predictable in statistical terms" (Lyon, Electronic Eye 194). The recognition of the simulated image will give the characters the illusion that they still have the ability to identify a needle in the haystack of all the confusing images and interface values of the mediascape of the city. They think that, by identifying the celebrity figure, they are identifying an ordinary fellow in the midst of this saturation. However, what they do is take shelter in an instance of the imagistic culture that has made them doubt and question their cognition faculties. In Idoru, using the capsule of image simulation is a desperate means for the characters to get away from an indifferent celebrity culture and return to a means or strategy through which personal connection and identification can be made possible. Even the possibility of the materialization of such a strategy necessitates consumption of the celebrity culture and its imagistic interface values that have filled the cyberpunk world of the novel and lobotomized most of the characters' faculties for recognizing, remembering and identifying ordinary faces. As Moylan argues, characters need to become helpers of (and complicit in) the system in order to "at least create a play in the order" (87). As his study acknowledges, the level of this playfulness is too minimal to even be noticed. In the novel, although characters' attempt to use purely capitalist and indifferent celebrity culture for their very personal and intuitive act of facial identification of criminals is commendable and can be regarded as a bold instance of negotiating with a capitalist system, they become so accustomed to one of these constructed images that they forget its artificial nature and the lack of any original attachment to such images.

One of the key effects of acquiring knowledge only through capsules is that in cyberpunk cities, capsularization of everything "has dwindled the size of public spaces" (Featherstone 21). People tend to accustom themselves to a series of routine preferences, and even seek fulfillment of these routine habits and preferences in places that do not immediately seem suitable. In Altered Carbon, the narrator indicates that people go to a public platform such as an airport to spend their weekend leisure time. In this activity, the airport public space becomes a safe and contained space of recognizable and convenient surface values for easy consumption. They prefer to stay in such an indoor atmosphere rather than experiencing the novelty of such places:

People even go to airport terminals to experience climate zones. There are a bunch of zones of micro-climates where palms and other less 
recognizable tropicalia made a bid for the massive glass ceiling. A misty rain drifted down from sprinkler systems, rendering the air pleasantly damp after the aridity outside. (Morgan 272)

The kind of represented airport with its simulation abilities of climate conditions is not only used as a terminal in which people are temporary sojourners, it is used as a place for leisure and experiences to which they do not have any direct access. The airport goes beyond its conventional consumptive objective and fulfills the ideology of consumption by creating the illusion of safety and convenience for its conventional and unconventional users. As De Cauter believes, "the economic logic of capsularization [turns] the outside world into [capsularized public spaces] unsafe and uncontrolled territory" (95). The quoted passage shows that people want to experience new exotic things such as different climate zones under the safe and commodified settings of a capsularized public space. This safe setting is capsularized in an airport whose conventional consumptive objectives have been radically changed. In such capsules, people do not expect "the diversity and unpredictability" that public spaces used to have and do not express any nostalgia (Davis 195). Yet, they know that their most personal and intimate cognition from a weather condition needs to be fulfilled in an airport, since it is gives them the illusion of a confined place for convenient and safe consumption.

The second consequence of the ideological necessity to consume through capsules in cyberpunk cities is to appropriate the conventional consumptive intentions behind formerly devised commodities through imagistic and interface commodities. Youngquist believes that "the economic importance of the consensual hallucination" replaces the battlefield as the primary site of strategic engagement (202). In this sense, consumption, regardless of the primary consumptive intention of both the old and new products, becomes the key objective of the cyberpunk world. In Gibson's All Tomorrow's Parties, the narrator describes advertisement billboards of a casino and how they can be used in unintended ways:

There were Lucky Dragons all over America, all over the world for that matter, and to prove it you had your trademark Lucky Dragon Global Interactive Video Column outside. You had to pass it entering and leaving the store, so you'd see whichever dozen Lucky Dragons the Sunset franchise happened to be linked with at that particular moment: Paris or Houston or Brazzaville, wherever. These were shuffled, every three minutes, for the practical reason that it had been determined that if the maximum viewing time was any more, kids in the world's duller suburbs would try to win bets by having sex on camera. (11) 
The passage evokes the loss of conventionality of interface values and images of the cyberpunk world. In this world, in order to have the maximum level of profit, media outlets need to let go of their insistence on being used and consumed in regulated ways and show some flexibility towards being used in unintended ways. These unintended ways are the result of a loss of "rigid determination" in favor of diffused consumption, which is instable, chaotic and impulsive, and is regulated only for the sake of consumption. William Mitchell believes that, in cybercity spaces, everything can be regarded as pure white noise. He argues that "you can do things in irrelevant contexts and settings. In this sense, everything can be regarded as white noise" (City of Bits 31). In the very example from All Tomorrow's Parties, public intercourse is a white noise among all the other spewing images and advertisements of the city. It is not a dissident or a "situationalist act," where people want to "re-enchant the ordinary with imposing unintended usage upon them" (Hubbard 108). The agenda of teenage couples' dissident act of public intercourse may be different from the agenda of the advertising casino. However, both wish to be gazed upon and consumed as image. What is important is that they use the very capsule in the capitalist network for their so-called dissident act of public obscenity, and, by doing this, magnify the advertisement objective of the billboard since some people may gaze upon the billboard for the sake of the scene between the couples and consume its advertising objective. In this regard, "the degree of capsularization is directly proportional to the growth of [the capitalist] network" of the city (De Cauter 96). In the cyberpunk world-like any cybernetic/informational city-the growth of the number of capsules advances to the extent that no dissident act or radical transgression can be regarded as separate from the consumptive affinities of society. In this manner every image or icon helps "the expandable mutability" of their intended and regulated usages so that the supreme objective of consumption can be realized (Lyon, Surveillance Society 34). This objective is rendered differently in Virtual Light. In this novel, one may see the grotesque superimposition of the useless junk of the present and the past over the bridge (which, as we discussed, is regarded as being artistic and an instance of Thomasson by many characters of the novel) as an instance of "junkartistic Ludditism represented by bridgescape" (Tatsumi 114). However, when compared with the detailed simulations of the sunglass - a capsularized gadget which works on the basis of pictorial data and "can see virtually not just the scene around you but also vivid, simulated scenes from the past"-the oppositional heterogeneity of the bridge against the streamline technophilic city is mitigated substantially (114). As mentioned earlier, capitalism always finds a way to achieve "its dream of commerce" through packaging the most dissident elements in 
conveniently devised packages. In Virtual Light, the nanaotechnological objectives of the sunglass to preserve a superficial image of the junkartisitc Ludditism of the past and at the same time pursue the capitalist objectives of the novel's corporate powers is indicative of the appropriative power which it as a capsule has over the cyberpunk denizens of the novel. All the characters seek to find the sunglass as the novel's key capsule since its version of the city is convenient, comprehensive and at the same time not overwhelming, and as a result annuls any possibility of commercially unwanted dissidence and genuine difference in the city.

The third consequence of a consumptive ideology in the cyberpunk world is to acquire a stereotypical and convenient tendency to communicate with people and things and categorize them. This tendency, as Mitchell believes, will show people's reliance on "standardized formats of fulfillment and consumption" (Cyborg Self 160). A critic such as Mitchell believes in cybernetic standardizations and sees the emergence of a cybernetic city as beneficial, culturally diversified, and inevitable. $\mathrm{He}$ thinks that, through such standardizations and capsules, cybercities will "make possible distance learning, telemedicine, telework, tele-mediated criminal justice systems and the replication of traditional urban structures and processes in cyberspace" (Warren et al. 51). In opposition to Mitchell, De Cauter's perspective on cybernetic advancements should be considered. He believes that, culturally, the plethora of imagistic capsules and their relative standardizations in informational cities only facilitate a higher degree of consumption at both the regional and international levels and have nothing to do with propagating culture or diversity.

According to such ideology, one can see in a novel such as Schismatrix Plus that the protagonist tends to think that a stereotypical understanding of Japanese is sufficient for everyday interaction, since it is the standardized version of the language used "without its unnecessary complicated honorific tenses" (9). What he calls complicated and unnecessary is the part of the Japanese language that is considered to be irrelevant since it cannot be marketed and put in convenient standardized capsules of a stereotypical "streamlined trade patois" for people to consume (9). In another example, even Laura, the dissident protagonist of Island in the Net, proves to have a shallow comprehension of other languages, since she has been raised in a corporate culture that is in touch with other communities only in order to sell more products to them. Her reaction to the way the couple speak in Hindi shows how clichéd and superficial her understanding of the Hindi language is:

$\mathrm{He}[\mathrm{Mr}$. Singh] and his wife began talking rapidly in Bengali or Hindi maybe, something incomprehensible, but speckled with English loan 
words. Like fighter jet and television. Mrs. Singh, whose name was Aratavari or something vaguely similar, took Laura into the parental bedroom. (Sterling, Island 156)

Her understanding of the Hindi and Bengali languages in a city that is filled with people with diverse cultures and languages is blandly naïve and shows that only the utilitarian objective of having a functional command or even superficial recognition of other languages and cultures is the objective of a cybercity. In All Tomorrow's Parties, characters continue to even insult the Japanese names. In this novel, Loveless, the representative of the corporate power, has a shallow understanding of the pronunciation of a foreign name (Yamazaki) and says: "Something Japanese. Something zaki, something zuki. Some shit like that" (Gibson, Parties 93). In this manner, he defends his incorrect pronunciation of the word. In this novel, the characters' tendency to continue their conventionally stereotyped and limited understanding of foreignness and novelties attests that their understanding remains capsularized and limited. Having been bombarded by different cultural affinities through superficial imagistic and interface values, the characters find themselves incapable of having genuine understanding and dialogue with these affinities and abide by the same convenient strategies of capitalism, which have been envisaged in the capsularized understanding of a foreign language. Although reference to a critic such as Moylan may sway us to see the positive emergence of a certain kind of playfulness on the part of the dominant culture towards other cultures and languages, one cannot overlook the domineering presence of capitalism with its homogenizing tendencies towards all signs of genuine difference and otherness. As Veronica Hollinger believes, such a presence may have prompted Jameson to argue that "science fiction is never about the future, but instead functions to dramatize our incapacity to imagine the future. In this gloomy construction, science fiction is incapable of imagining futures that might be qualitatively different from the present" (199). This commentary is a testimony to the bland stereotypical tendency of any capsularized novelty in the capitalist world of cyberpunk fiction which only reflects superficial difference and cultural variance but never supports genuine understanding of otherness.

The absence of genuine engagement with cultures and languages materializes the fourth consequence of the ideological need to consume through capsules. Under such circumstances, one fails to see genuine differences amidst all these imagistic and interface values of a cyberpunk city. According to Diana Eck, a prominent scholar in pluralistic studies of cultures and religions, the abundance of images and surface values with seemingly different cultural origins does not necessarily result in the 
presence of genuine pluralism. She states that a pluralistic community has four main features:

First, pluralism is not diversity alone, but the energetic engagement with diversity. . . . Mere diversity without real encounter and relationship will yield increasing tensions in our societies. Second, pluralism is not just tolerance, but the active seeking of understanding across lines of difference. ... Third, pluralism is not relativism, but the encounter of commitments. It means holding our deepest differences not in isolation, but in relationship to one another. Fourth, pluralism is based on dialogue.... Dialogue means both speaking and listening, and that process reveals both common understandings and real differences. (Eck)

Engagement with diversity, understanding of differences, and becoming committed to diversities and dialogue are the key concepts of pluralism. However, cyberpunk cities treat genuine differences and similarities of cultures and languages superficially and such a treatment results in simultaneous "boredom and anxiety," according to the narrator in Idoru. He says: "[Through the combination] of boredom and anxiety, cities start to look the same. One hotel room after another. It's a syndrome, is what it is" (Gibson, Idoru 80). According to Eck, this anxiety is due to the lack of genuine dialogue and commitment to understanding each other in imagistic cities such as cyberpunk cities. Such cities only yearn to present a workable version of pluralism, since it is the only practical and economic version through which either a bland, comfortable sameness or a safe, riskless difference can be commodified for both the regional and international users of our world. The idea behind standardizing hotels in key cities of the world is the corporate way to provide users with capsules with which they can protect themselves from overwhelming imagistic newness of today's world. Idoru emphasizes that the excessive newness of the city is a tiresome reminder of each other. This tendency is not an indicator of a similar deep structure under the abundance of surface values, but is an indicator of minimal differential criteria on which these surface values and their differences are realized. It is minimal and imperceptible to the extent that their continuation may create boredom in the citizens of the represented city. The existence of minimal differences is represented in the similarities one can find between cyberpunk versions of Tokyo and Seattle in Idoru:

... [E]very little detail of Tokyo, was just different enough to create a kind of pressure, something that built up against her eyes, as though they'd grown tired of having to notice all the differences: a little sidewalk tree that was dressed up in a sort of woven basketwork jacket, the neonavocado color of a payphone and a serious-looking girl with round 
glasses.... She felt that if she squinted, maybe, just the right way, she could make all this turn back into Seattle, some downtown part she'd walked through with her mother. (Gibson, Idoru 107)

The icons and the signs, which are parts of Tokyo's unique urban identity, can also be applied to a city like Seattle with only a slight manipulation ("if she squints”). Finding this uniformity in the most different images and surface values creates straight jacket cultures which lack genuine differences. The lack of genuine differences causes such cultures to fail to have a pluralistic understanding of sameness and differences. Identification of such boring similarities in differences will only ease the level of tolerance people have with each other, which in Eck's terminology cannot be defined as a sign of a pluralistic society that can offer genuine cultural dialogue and social justice- the things that Mitchell thinks can be achieved in a cybercity with a "we-can-do-anything-digitally" motto.

Capsules of the cyberpunk city are successful in attaining their consumptive objective since they are represented as the only coping means against the shock of assailment of all the technological, cybernetic and cultural abundance of the cyberpunk world. Boring standardizations of the shocking plethora of newness in the city through superficial novelties; , the characters' inclination towards the acquisition of the superficial and surface knowledge from the represented cultures, allowing them to consume cyberpunk commodities in unintended ways, and making the emergence of genuine cultural dialogue and pluralism impossible for the sake of their convenient consumption: these are the consequences with which cyberpunk capsules add a sense of consumptive allure for themselves. With them, an informational city such as a cyberpunk city turns consumption of its soft capitals (e.g., image and interface values) into an ideological necessity for the characters.

\section{CONCLUSION}

This study has argued that images and interface values are the nova of the cyberpunk world through which all the other novelties of this world are devised and presented. The study also showed that identifying images and interface values as the key nova of cyberpunk fiction acknowledges the late capitalist nature of the genre. This leads the genre towards relying on what Jameson believes to be the "excess of representation" through which the coupling of genuine thoughts and ideas with consumable commodities becomes possible (321). In other words, through blending unfamiliar concepts with familiar ones, cyberpunk fiction makes possible the survival 
of both the nuanced and unfamiliar concepts, and the capitalistically familiar ones. Furthermore, this blend also causes the easy acceptance and consumption of all novelties of the cyberpunk world by its denizens, and as a result fulfils the objective of consumption as the only undeniable and unshakable deep structure of this world.

Alongside considering images and interface values as the nova of cyberpunk fiction, the study regarded them as science fictional capsules. This understanding showed us that most characters utilize the imagistic nova as protective capsules against the overwhelming presence of all the different kinds of nova and cybernetic advancements in the cyberpunk world. Although characters do get to manipulate the intended capitalist objectives of some of the nova and advancements through capsularizing them in their own favor, they fail to escape the conveniently standardized and capitalist deep structure of these capsules, whose key objective is to promote consumption among the denizens of the cyberpunk world. Such understanding of even the capsularized images and interface values of the cyberpunk world — as the key nova of this science fictional world-is dialectic (and, as mentioned earlier, not recidivist), and as a result does not see genuine dissidence and agency in their appropriations by characters or in their superficial display of otherness and pluralism. What it sees is a ludic playfulness which has been created by capsularized images and interface values against their own overabundance. The characters in the novels examined here can only deal with this overabundance when they choose some of these capsules and become involved in their playfulness and ultimately consumptive nature. In their absolute capitalist involvement, they may occasionally get the opportunity to exercise the most minimal and transient level of agency through capsularization of the consumptive and standardizing attack of images and interface values. However, due to the fact that images and interface values are the building blocks of the capsules, characters never get the chance to attain any vestige of true subjectivity, agency or dissidence. They only learn to survive by abiding and minimally manipulating the consumptive ideology of the dominant system.

\section{Works Cited}

Davis, Mike. "Fortless L.A." The City Reader. Ed. Richard T. LeGates and Fredric Stout. London: Routledge, 1996. 193-98. Print.

De Cauter, Lieven. "The Capsule and the Network: Notes Towards a General Theory.” The Cybercities Reader. Ed. Steve Graham. London: Routledge, 2004. 94-97. Print. 
Eck, Diana. "What is Pluralism?" Pluralism.org. The Pluralism Project 2006. Web. Feb. 2019.

Featherstone, Mike. Cyberspace, Cyberbodies and Cyberpunk. Thousand Oaks: Sage, 1995. Print.

Gibson, William. All Tomorrow's Parties. New York: Viking, 1999. Print.

Gibson, William. Idoru. New York: Viking, 1996. Print.

Gibson, William. Virtual Light. New York: Viking, 1993. Print.

Hollinger, Veronica. "Retrofitting Frankenstein." Beyond Cyberpunk: New

Critical Perspectives. Ed. Graham J. Murphy and Sherryl Vint. New York: Routledge, 2010. 191-210. Print.

Hubbard, Phil. City. London: Routledge, 2006. Print. https://doi. org/10.4324/9780203392256

Jameson, Fredrick. Postmodernism: Or the Cultural Logic of Late Capitalism. Durham:Duke UP,1991.Print. https://doi.org/10.1215/9780822378419

Lyon, David. Surveillance Society: Monitoring Everyday Life. London: Open UP, 2001. Print.

Lyon, David. The Electronic Eye: The Rise of Surveillance Society. Minneapolis: U of Minnesota P, 1994. Print.

Mitchell, William J. City of Bits. Cambridge: MIT, 1995. Print.

Mitchell, WilliamJ.Me++:The Cyborg Selfand the Networked City. Cambridge: MIT, 2003. Print. https://doi.org/10.7551/mitpress/4512.001.0001

Morgan, Richard. Altered Carbon. London: Orion, 2002. Print.

Moylan, Tom. "Global Economy, Local Text: Utopian/Dystopian Tension in William Gibson's Cyberpunk Trilogy.” Beyond Cyberpunk: New Critical Perspectives. Ed. Graham J. Murphy and Sherryl Vint. New York: Routledge, 2010. 81-94. Print.

Roberts, Adam. Science Fiction. London: Routledge, 2000. Print.

Sterling, Bruce. Island in the Net. Michigan: Arbor, 1988. Print.

Sterling, Bruce. Schismatrix Plus. New York: ACE, 1996.

Tatsumi, Takayuki. Full Metal Apache: Transactions Between Cyberpunk Japan and Avant-Pop America. Durham: Duke UP, 2006. Print. https:// doi.org/10.1215/9780822388012

Vint, Sherryl. "The Mainstream Finds its Own Uses for Things: Cyberpunk and Commodification." Beyond Cyberpunk: New Critical Perspectives. Ed. Graham J. Murphy and Sherryl Vint. New York: Routledge, 2010. 95-115. Print.

Warren, Robert, et al. "The Future of the Future in Planning: Appropriating Cyberpunk Visions of the City." Journal of Planning Education and Research 18 (1998): 49-60. Print. https://doi. org/10.1177/0739456X9801800105

Youngquist, Paul. Cyberfiction. New York: Palgrave Macmillan, 2010. Print. https://doi.org/10.1057/9780230106215 
Hossein Mohseni holds a PhD in English Language and Literature from Shahid Beheshti University, Iran, where he also completed his B.A. and M.A. in the same field. He worked on cyberpunk fiction in his $\mathrm{PhD}$ dissertation which is entitled "City Spaces in Cyberpunk Fiction." "Formable Fluidity: The Key Consequence of Information Flow in Cyberpunk Fiction" and "The Eye/I of the Storm: The Hollowness of Identity and Knowledge of Posthuman Subjects in Cyberpunk Fiction" are two of his recent publications. Coauthored by Kian Soheil, the mentioned articles have respectively been published in American and British Studies Annual and Critical Language and Literary Studies. His interests include science fiction, literary theory and criticism, and modern drama.

ORCID: 0000-0003-0509-7959

h_mohseni@sbu.ac.ir

Kian Soheill is Assistant Professor of English Literature at the Department of English Language and Literature, Faculty of Letters and Human Sciences, Shahid Beheshti University, Iran, where he has taught since the completion of his $\mathrm{PhD}$ at King's College London, UK, in 1999. His interests include mythology, Victorian Literature, and drama.

ORCID: 0000-0002-8883-4426

k-soheil@sbu.ac.ir 